\title{
Characterization of Chromosome-Mediated Bla OXA-894 in Shewanella xiamenensis Isolated from Pig Wastewater
}

\author{
Huiyun Zou, Ziyu Zhou, Huiyu Xia, Qian Zhao and Xuewen Li * \\ Department of environment and health, School of Public Health, Shandong University, Jinan 250012, China; \\ zouhuiyun@mail.sdu.edu.cn (H.Z.); zhouziyu199622@mail.sdu.edu.cn (Z.Z.); \\ mosebyxhy@mail.sdu.edu.cn (H.X.); 201835834@mail.sdu.edu.cn (Q.Z.) \\ * Correspondence: 1xw@sdu.edu.cn; Tel.: +86-0531-8838-2138
}

Received: 28 August 2019; Accepted: 3 October 2019; Published: 8 October 2019

\begin{abstract}
A new variant of the bla $a_{\mathrm{OXA}-546}$ gene, namely $b l a_{\mathrm{OXA}-894}$, was identified on the chromosome of Shewanella xiamenensis isolated from pig wastewater in rural China. OXA-894 differs from OXA-546 (A46V, I219del) and OXA-48 (T167I, I219del) with two amino acid substitutions, respectively. The isolate was resistant to ampicillin, aztreonam, imipenem, meropenem and fosfomycin. Carba NP test confirmed S. xiamenensis strain sx20 as a carbapenemase-producer. The bla $a_{\mathrm{OXA}-894}$ gene was located between the gene encoding a LysR family transcriptional regulator and the $\mathrm{C} 15$ gene. Its gene environment was similar to other $S$. xiamenensis with chromosome-located bla $a_{\text {OXA-48-like genes. }}$ The $\mathrm{T} 24 \mathrm{H}$ and $\mathrm{T} 94 \mathrm{~V}$ amino acid substitutions of $L u x S$ protein were predicted to be deleterious, which may affect the virulence phenotype. The occurrence and potential health risk of carbapenem-resistant S. xiamenensis in a water environment is of concern.
\end{abstract}

Keywords: bla $a_{\mathrm{OXA}-894 ;}$ Shewanella xiamenensis; genetic environment; pig wastewater

\section{Introduction}

The $b l a_{\mathrm{OXA}-48}$ gene, encoding class D beta-lactamases, was first reported in Klebsiella pneumoniae from a patient with urinary tract and skin burns in Turkey in 2001 [1]. The enzyme usually hydrolyzed penicillins at high levels, but hydrolyzed carbapenems at a low level [2]. Bla OXA-48-like genes were widely reported among K. pneumoniae and other Enterobacteriaceae [3]. To date, 91 bla OXA-48-like variants have been identified, with classical $b l a_{\mathrm{OXA}}-48$ being the most widespread [4-7]. Bla $a_{\mathrm{OXA}-48}-1$ ike gene carriers caused outbreaks of nosocomial and community infections in many countries, including China $[3,8]$. The number of reservoirs for these organisms was increasing among humans, animals and in the environment [3]. Thus, the rapid dissemination of carbapenem-resistant species harboring

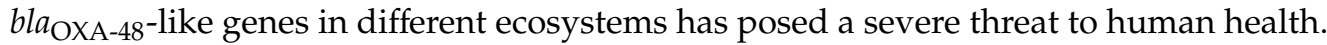

Shewanella xiamenensis, Gram-negative rods, $0.7-0.8 \times 2.5-4.0 \mu \mathrm{m}$, was isolated from coastal sediments for the first time in China [9]. S. xiamenensis was usually detected in the marine and freshwater environment, and rarely isolated from an animal source [10]. It has become an emerging pathogen contributing to intestinal colonization and abdominal cavity infection [11]. S. xiamenensis has been regarded as a progenitor of OXA- 48 family class D beta-lactamase [12]. The chromosome-mediated $b l a_{\mathrm{OXA}}-48$-like genes may be mobilized onto plasmids by insertion sequences, then plasmids could be transferred to clinically relevant pathogens (such as Escherichia coli). Increasing numbers of $b l a_{\mathrm{OXA}-48}$-variants were reported in S. xiamenensis from human and environmental sources, such as $b l a_{\text {OXA-181 }}, b l a_{\text {OXA-199, }}, b l a_{\text {OXA-204, }}$ and $b l a_{\text {OXA-538 }}$ [13-16]. Thus, the purpose of this study was to characterize a gene belonging to the $b l a_{\mathrm{OXA}-48}$ family, and investigate its genetic environment in S. xiamenensis. 


\section{Materials and Methods}

\subsection{Bacterial Isolate}

In July 2015, 36 backyard farms were randomly selected in rural China and wastewater was sampled from the storage pool, which was located near the pig farms, using sterilized bottles. Water samples were filtered through $0.45 \mu \mathrm{m}$ sterile membrane filters (Millipore, MA, USA), then membranes were inoculated in brain heart infusion broth (Oxoid, Basingstoke, UK) and cultured at $37{ }^{\circ} \mathrm{C}$ overnight. The enriched solutions $(100 \mu \mathrm{L})$ were plated on MacConkey agar (Oxoid, Basingstoke, UK) with $2 \mathrm{mg} / \mathrm{L}$ meropenem (Meilun, Dalian, China) to isolate potential carbapenem-resistant isolates. The presence of the carbapenemase-encoding genes (bla $a_{\mathrm{NDM}-}, b l a_{\mathrm{KPC}-}, b l a_{\mathrm{IMP}-}$ and $\left.b l a_{\mathrm{OXA}-48^{-t y p e s}}\right)$ in the potential isolates were tested by using PCR and sequencing (Biosune, Shanghai, China), as described previously [17]. Species confirmations were performed by matrix-assisted laser desorption ionization-time-of-flight mass spectrometry (bioMérieux, Lyon, France), sequencing of the 16S rRNA and gyrB genes.

\subsection{Antibiotic Susceptibility Testing}

The minimum inhibitory concentrations (MICs) of S. xiamenensis strain sx20 were determined using the broth microdilution method with the following agents: amikacin, ampicillin, ampicillin-sulbactam, aztreonam, cefazolin, ceftazidime, cefotetan, ceftriaxone, cefepime, ciprofloxacin, ertapenem, fosfomycin, gentamicin, imipenem, levofloxacin, meropenem, nitrofurantoin, piperacillin-tazobactam, tobramycin (Meilun, Dalian, China). The control strain was E. coli ATCC 25922. The results were interpreted according to EUCAST guidelines. Phenotypic detection of carbapenemase was performed using the Carba-direct NP test [18]. Bacteria were cultured on Mueller-Hinton agar overnight (Oxoid, Basingstoke, UK). The bacterial mass was scraped off with a $1-\mu \mathrm{L}$ loop and suspended in a $1.5-\mathrm{mL}$ Eppendorf tube containing $100 \mu \mathrm{L}$ of $20 \mathrm{mM}$ Tris- $\mathrm{HCl}$ lysis buffer. This lysate was mixed with $100 \mu \mathrm{L}$ of an aqueous indicator solution which contained $0.05 \%$ phenol red with $0.1 \mathrm{mmol} / \mathrm{L} \mathrm{ZnSO}_{4}$ and $6 \mathrm{mg} / \mathrm{mL}$ imipenem, and the phenol red solution without antibiotic as a control tube.

\subsection{Whole-Genome Sequencing and Analysis}

The entire genome of $S$. xiamenensis strain sx20 was sequenced using whole-genome sequencing (WGS) analysis using an Illumina HiSeq 4000-PE150 platform (Illumina, CA, USA). The sequences were assembled using SPAdes 3.11 and annotated via RAST (http://rast.nmpdr.org/). Antibiotic resistance genes and virulence genes were analyzed by Resfinder (https://cge.cbs.dtu.dk/services/ResFinder/) and the Virulence Factor Database (VFDB, http://www.mgc.ac.cn/VFs/). The genetic environment was visualized by Easyfig 2.2.3. Clustal Omega (https://www.ebi.ac.uk/Tools/msa/clustalo/) and Jalview [19] were used to perform the alignment analysis of amino acid sequences. The effect of the biological function of a protein caused by amino acid substitution or indel was predicted by PROVEAN (http://provean.jcvi.org/). The sequencing data of the whole genome and bla OXA-894 gene was deposited under the GenBank accession number SUNE00000000 and MN525568, respectively.

\subsection{The Conjugation Assay}

The conjugation experiment was carried out using the mixed broth method as previously described [20]. Conjugation was performed using E. coli J53 (sodium azide-resistant) as the recipient strain. Transconjugants were selected on LB agar plates (Oxoid, Basingstoke, UK) supplemented with sodium azide $(100 \mathrm{mg} / \mathrm{L})$ and meropenem $(2 \mathrm{mg} / \mathrm{L})$.

\subsection{Phylogenetic Analysis of the Bla OXA-48-Like Genes}

A phylogenetic tree of bla $a_{\mathrm{OXA}-48}$-like genes was constructed by the MEGA X software [21] using the maximum likelihood method with 1000 bootstrapping. The representative sequences and closest 
references were collected from the GenBank database, including bla OXA-10 (NG_049393), bla OXA-48 (NG_049762), bla OXA-48b (KC902850), bla OXA-54 (NG_049794), bla $a_{\text {OXA-162 }}$ (NG_049461), bla OXA-181 (KX298210), bla OXA-199 (NG_049495), bla OXA-204 (KC902852), bla OXA-244 (NG_049539), bla OXA-252 (NG_050608), bla OXA-416 (KU198597), bla OXA-515 (NG_055476), bla OXA-538 (KX827284), bla OXA-546 (NG_054959), bla OXA-894 (MN525568) and bla OXA-547 (NG_054693).

\section{Results and Discussion}

In our study, S. xiamenensis strain sx20 was isolated from pig wastewater in rural China. It was resistant to ampicillin, aztreonam, ertapenem, imipenem, meropenem and fosfomycin. The Carba NP test showed it was a carbapenemase producer. Carbapenem MICs of S. xiamenensis strain sx20 were similar to $S$. xiamenensis IR34 harboring bla OXA-204 $_{\text {gene }}$ and S. xiamenensis DDP1 harboring bla OXA-416 (Table 1), but higher than strains of IR24 and IR33 harboring bla $a_{\mathrm{OXA}-48}$ gene and S12-harboring $b l a_{\mathrm{OXA}-181}$ gene $[12,13,22]$, indicating there may be additional mechanisms for regulating carbapenem resistance in S. xiamenensis.

Table 1. The carbapenem MICs (mg/L) of S. xiamenensis harboring bla $a_{\mathrm{OXA}-48}$-like genes.

\begin{tabular}{|c|c|c|c|c|c|c|}
\hline Species & Year & $b l a_{\text {OXA-48 }}$-Like Gene & Imipenem & Meropenem & Ertapenem & Reference \\
\hline S. xiamenensis IR33 & 2013 & $b l a_{\mathrm{OXA}-48}$ & 4 & 1 & 8 & [12] \\
\hline S. xiamenensis Sh31 & 2018 & $b l a_{\mathrm{OXA}}-48$ & 8 & 2 & 8 & [14] \\
\hline S. xiamenensis IR24 & 2013 & $b l a_{\text {OXA-48 }}$-like & 4 & 2 & 8 & [12] \\
\hline S. xiamenensis $\mathrm{S} 12$ & 2011 & $b l a_{\mathrm{OXA}-181}$ & 0.75 & 0.25 & 2 & [13] \\
\hline S. xiamenensis Sh5 & 2018 & $b l a_{\text {OXA-181 }}$ & 4 & 5 & 4 & [14] \\
\hline S. xiamenensis AS69 & 2017 & $b l a_{\text {OXA-181 }}$ & 0.75 & - & - & [16] \\
\hline S. xiamenensis AS85 & 2017 & $b l a_{\text {OXA-181 }}$ & 0.75 & - & - & [16] \\
\hline S. xiamenensis AS100 & 2017 & $b l a_{\text {OXA-199 }}$ & 0.5 & - & - & [16] \\
\hline S. xiamenensis IR34 & 2013 & $b l a_{\text {OXA-204 }}$ & $>32$ & 8 & $>32$ & [12] \\
\hline S. xiamenensis Sh33 & 2018 & $b l a_{\text {OXA-204 }}$ & $>32$ & 8 & $>32$ & [14] \\
\hline S. xiamenensis ZYW1 & 2019 & $b l a_{\text {OXA-416 }}$ & 1 & - & - & [10] \\
\hline S. xiamenensis DDP1 & 2013 & $b l a_{\text {OXA- } 416}$ & 32 & 16 & $>32$ & [22] \\
\hline S. xiamenensis $\mathrm{T} 17$ & 2017 & $b l a_{\text {OXA-416 }}$ & 1 & 1 & 4 & [23] \\
\hline S. xiamenensis AS58 & 2017 & $b l a_{\text {OXA-538 }}$ & 3 & - & - & [16] \\
\hline S. xiamenensis Sh1 & 2018 & $b l a_{\text {OXA-546 }}$ & 1 & 0.5 & 3 & [14] \\
\hline S. xiamenensis sx20 & 2019 & $b l a_{\text {OXA-894 }}$ & 32 & 8 & 8 & This study \\
\hline
\end{tabular}

One antibiotic resistance gene was identified in S. xiamenensis strain sx20. It is a new variant of the bla $a_{\text {OXA-546 }}$ gene, namely bla OXA-894 (MN525568), which was $99.75 \%$ and $99.12 \%$ nucleotide identity to $b l a_{\text {OXA-546 }}$ (KY682756) and bla OXA-48 (NG_049762). The OXA-894 differs from OXA-546 (A46V, I219del), OXA-48 (T167I, I219del) with two amino acid substitutions, respectively (Figure 1). The conjugation experiment was not successful in transferring bla OXA-894 gene to E. coli J53. The result of WGS confirmed that the bla $a_{\mathrm{OXA}-894}$ gene was located on the chromosome. A number of chromosome-mediated $b l a_{\mathrm{OXA}}-48$-like genes have been reported in S. xiamenensis, including bla OXA-181 gene [13], bla OXA-199 gene [15], bla $a_{\mathrm{OXA}-416}$ gene [23] and bla $a_{\mathrm{OXA}-538}$ gene [16]. Given this, our identification further supported the hypothesis that $S$. xiamenensis was the progenitor of $b l a_{\mathrm{OXA}}-48$-like genes.

The results of the phylogenetic analysis (Figure 2) showed that the bla OXA-894 gene formed a cluster with the $b l a_{\text {OXA-546, }}, b l a_{\text {OXA-48b }}, b l a_{\text {OXA-547 }}$ gene sequences detected in S. xiamenensis. The first such $b l a_{\mathrm{OXA}-48}-$ like gene in $S$. xiamenensis to be reported was from India, in 2011, namely bla OXA-181 gene, which has activity against carbapenems [13]. Until now, at least $10 b l a_{\mathrm{OXA}-48^{-}}$like variants have been identified in the S. xiamenensis from India, China, Portugal, Italy and Algeria, including $b l a_{\text {OXA-48 }}, b l a_{\text {OXA-48b }}, b l a_{\text {OXA-181 }}, b l a_{\text {OXA-199 }}, b l a_{\text {OXA-204 }}, b l a_{\text {OXA-416 }}, b l a_{\text {OXA-538 }}, b l a_{\text {OXA-546 }}, b l a_{\text {OXA-894 }}$ and

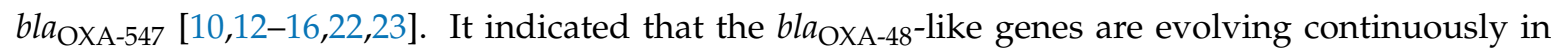
different regions. 


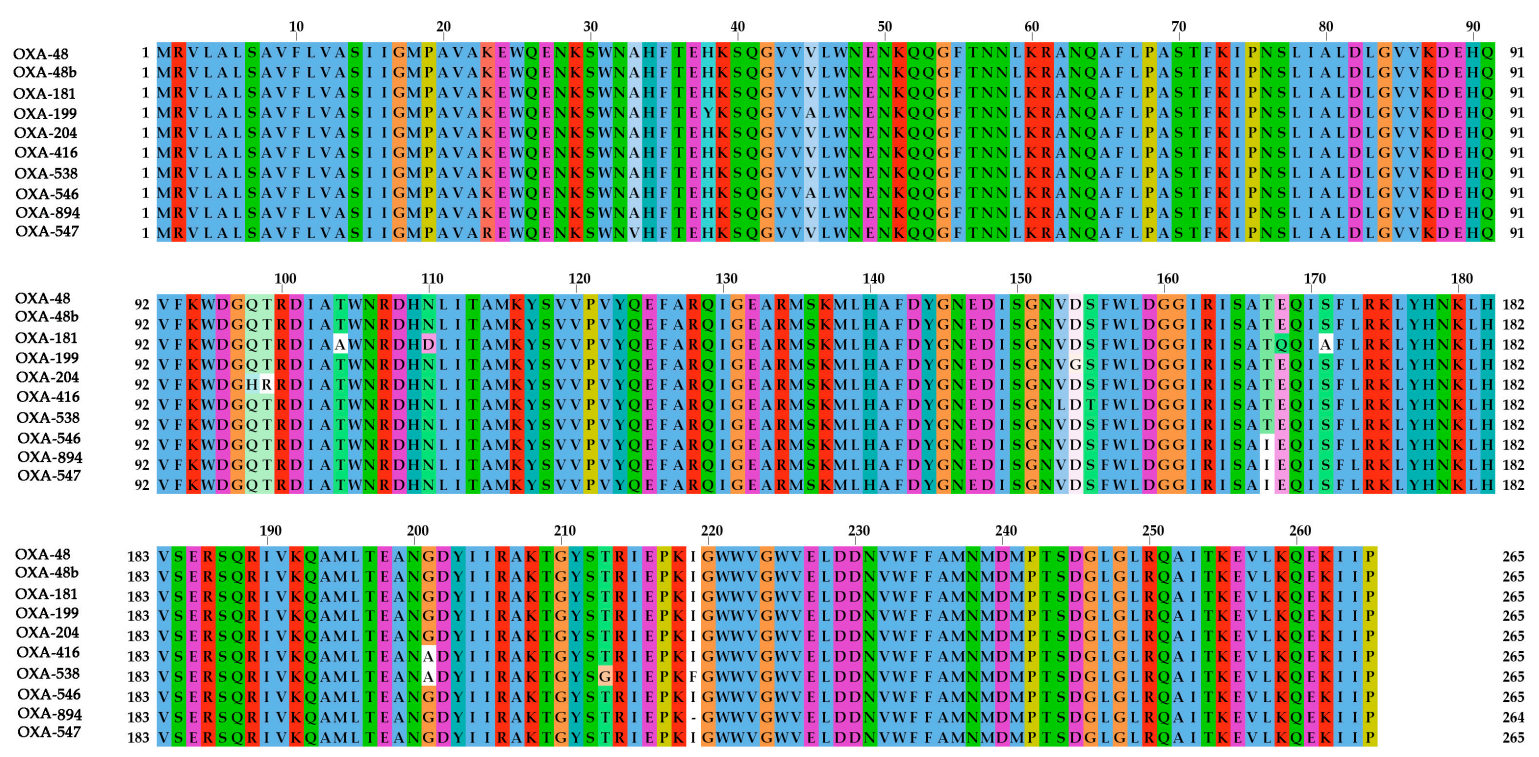

Figure 1. Alignment of the amino acid sequences of OXA-48 (WP_015059991), OXA-48b (AGS78031), OXA-181 (AQU42625), OXA-199 (WP_063861505), OXA-204 (AGS78037), OXA-416 (APO14326), OXA-538 (WP_071593227), OXA-546 (WP_087587945), OXA-894 (MN525568) and OXA-547 (WP_085562403).
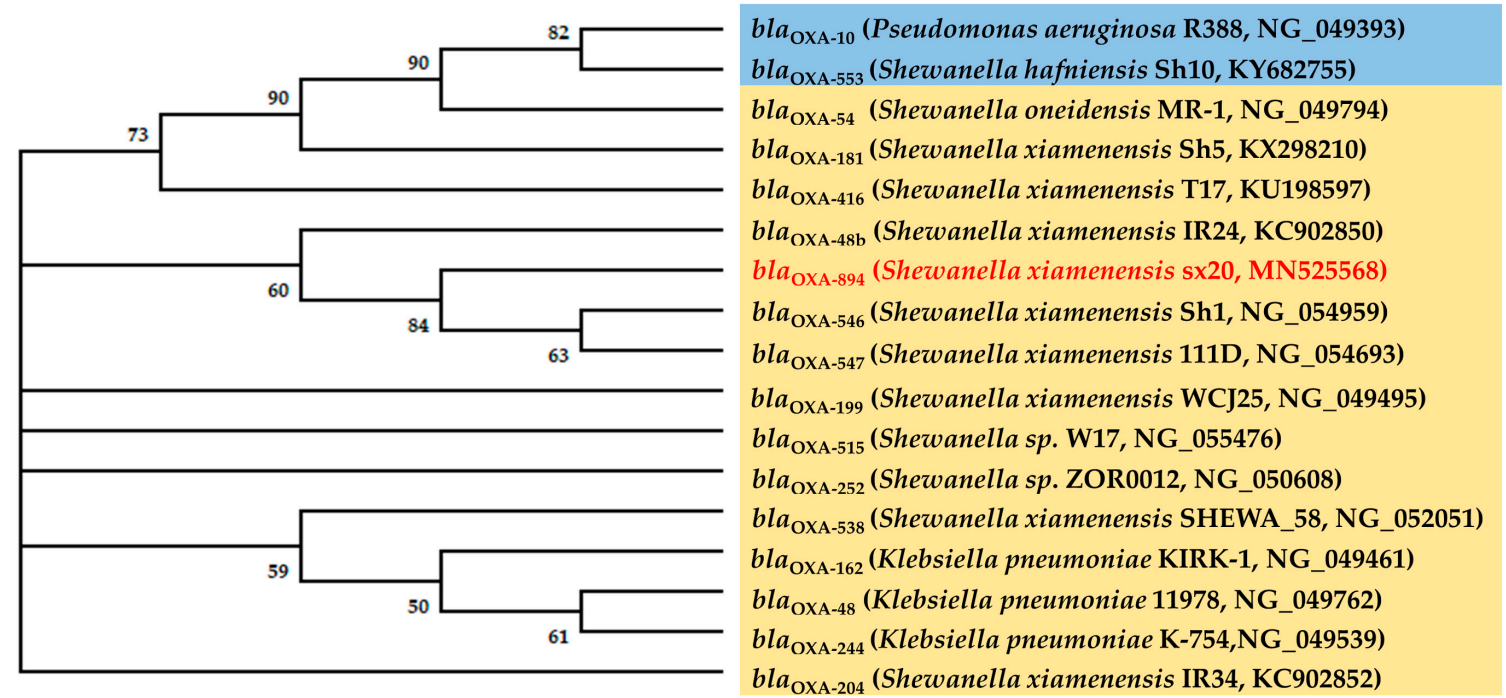

Figure 2. Molecular phylogenetic analysis using maximum likelihood method with 1000 bootstraps of bla $a_{\mathrm{OXA}-894}$ with closest matches and representative nucleotide sequences retrieved from the GenBank database. The phylogenetic tree was constructed using MEGA X software. Bootstrap confidence is shown in \%. The bla OXA-48-like genes are shown in yellow boxes, and other genes are highlighted in blue boxes.

Bla $a_{\text {OXA-546 }}$ was first reported in the plasmid of S. xiamenensis Sh1 isolated from saltmarsh plants in the USA, 2018 [14]. However, the chromosome-mediated bla $a_{\mathrm{OXA}-546}$ gene has not been reported until now. In the current study, the single copy of the bla OXA-894 gene was found in S. xiamenensis sx20. It was located on the chromosome and inserted between the LysR family transcriptional regulator and the C15 gene (Figure 3). The genetic context of $b l a_{\mathrm{OXA}-894}$ was similar to that previously reported for other $b l a_{\mathrm{OXA}-48}$-like genes in the Shewanella species [14]. The occurrence of bla $a_{\mathrm{OXA}-894}$ can increase the diversity of chromosome-mediated carbapenem-hydrolyzing class D $\beta$-lactamase genes in Shewanella species. No mobile element was found upstream and downstream of the bla $a_{\mathrm{OXA}-894}$ gene in $S$. xiamenensis strain sx20, indicating a low probability of horizontal gene transfer. But bla $a_{\mathrm{OXA}} 894$ gene was detected in an 
isolate from water, an environment that can be frequently affected by anthropogenic activities (such as discharges of wastewater), which may potentiate the spread of this gene in the environment, in animals and in humans. Therefore, the occurrence and potential health risk of carbapenem-resistant $S$. xiamenensis in water environment needs to be concerned.

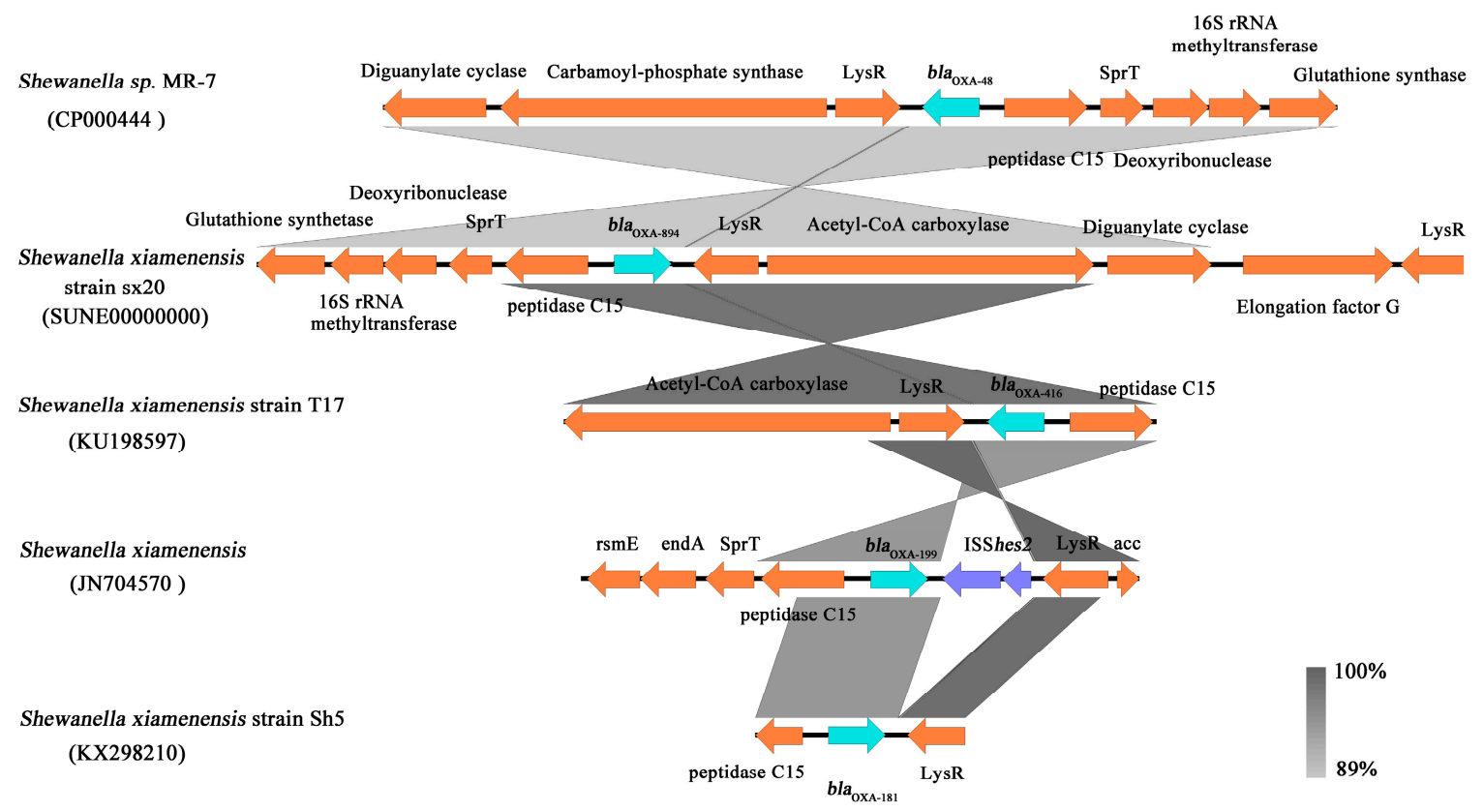

Figure 3. The genetic context of bla $a_{\mathrm{OXA}-48}$-like gene in S. xiamenensis strain sx20 (SUNE00000000), Shewanella spp. MR-7 (CP000444), S. xiamenensis strain T17 (KU198597), S. xiamenensis strain WCJ25 (JN704570) and S. xiamenensis strain Sh5 (KX298210). Comparisons between multiple sequences were performed using Easyfig 2.2.3. Open reading frames are shown as arrows indicating the orientation of each gene. The gene name is shown over the corresponding arrow.

According to the virulence factor database, only the $l u x S$ gene was detected with $82 \%$ nucleotide identity with wild type $\operatorname{luxS}$ (NC_000913). The deduced LuxS protein differs from wild-type LuxS (NP_417172) by 44 amino acid substitutions, and the T24H and T94V substitutions were predicted to be deleterious by PROVEAN. The luxS gene in the Shewanella encodes an autoinducer-2-like molecule which was the postulated universal bacterial signal. The mutants of the $\operatorname{lux} S$ gene could influence the biofilm formation, production of virulence factors and motility of pathogenic bacteria [24]. It indicated that the mutants of $l u x S$ gene may affect the virulence phenotype of the S. xiamenensis strain sx 20 .

\section{Conclusions}

This is the first report of chromosome-mediated $b l a_{\mathrm{OXA}-894}$ gene in S. xiamenensis. The OXA-894 differs from OXA-546 (A46V, I219del), OXA-48 (T167I, I219del) with two amino acid substitutions, respectively. Bla $\mathrm{OXA}-894$ gene was inserted between the LysR family transcriptional regulator and $\mathrm{C} 15$ gene. The occurrence of bla $a_{\mathrm{OXA}-894}$ can increase the diversity of chromosome-encoded carbapenem-hydrolyzing class D $\beta$-lactamases identified in Shewanella species. A mutated luxS gene was also identified in this strain, which may affect the virulence phenotype of S. xiamenensis. The occurrence and potential health risk of carbapenem-resistant bacteria in the water environment is of concern.

Author Contributions: X.L. designed the study; H.X. and Q.Z. contributed to the sampling; H.Z. and Z.Z. performed the experiments; H.Z. analyzed the data and wrote the manuscript. All authors reviewed and revised the manuscript.

Funding: The Fundamental Research Funds of Shandong University: 2018JC102; The National Natural Science Foundation of China: 41771499. 
Acknowledgments: This project was supported by the National Natural Science Foundation of China (41771499, 813111250), and the Fundamental Research Funds of Shandong University (2018JC102).

Conflicts of Interest: The authors declare no conflicts of interest.

\section{References}

1. Poirel, L.; Heritier, C.; Tolun, V.; Nordmann, P. Emergence of oxacillinase-mediated resistance to imipenem in Klebsiella pneumoniae. Antimicrob. Agents Chemother. 2004, 48, 15-22. [CrossRef] [PubMed]

2. Poirel, L.; Potron, A.; Nordmann, P. OXA-48-like carbapenemases: The phantom menace. J. Antimicrob. Chemother. 2012, 67, 1597-1606. [CrossRef] [PubMed]

3. Mairi, A.; Pantel, A.; Sotto, A.; Lavigne, J.P.; Touati, A. OXA-48-like carbapenemases producing Enterobacteriaceae in different niches. Eur. J. Clin. Microbiol. Infect. Dis. 2018, 37, 587-604. [CrossRef] [PubMed]

4. Kasap, M.; Torol, S.; Kolayli, F.; Dundar, D.; Vahaboglu, H. OXA-162, a novel variant of OXA-48 displays extended hydrolytic activity towards imipenem, meropenem and doripenem. J. Enzym. Inhib. Med. Chem. 2013, 28, 990-996. [CrossRef] [PubMed]

5. Potron, A.; Nordmann, P.; Lafeuille, E.; Al Maskari, Z.; Al Rashdi, F.; Poirel, L. Characterization of OXA-181, a carbapenem-hydrolyzing class D beta-lactamase from Klebsiella pneumoniae. Antimicrob. Agents Chemother. 2011, 55, 4896-4899. [CrossRef] [PubMed]

6. Potron, A.; Nordmann, P.; Poirel, L. Characterization of OXA-204, a carbapenem-hydrolyzing class D beta-lactamase from Klebsiella pneumoniae. Antimicrob. Agents Chemother. 2013, 57, 633-636. [CrossRef]

7. Potron, A.; Rondinaud, E.; Poirel, L.; Belmonte, O.; Boyer, S.; Camiade, S.; Nordmann, P. Genetic and biochemical characterisation of OXA-232, a carbapenem-hydrolysing class D beta-lactamase from Enterobacteriaceae. Int. J. Antimicrob. Agents 2013, 41, 325-329. [CrossRef]

8. Guo, L.; An, J.; Ma, Y.; Ye, L.; Luo, Y.; Tao, C.; Yang, J. Nosocomial Outbreak of OXA-48-Producing Klebsiella pneumoniae in a Chinese Hospital: Clonal Transmission of ST147 and ST383. PLoS ONE 2016, 11, e0160754. [CrossRef]

9. Huang, J.; Sun, B.; Zhang, X. Shewanella xiamenensis sp. nov., isolated from coastal sea sediment. Int. J. Syst. Evol. Microbiol. 2010, 60, 1585-1589. [CrossRef]

10. Huang, Y.; Cheng, J.; Wu, Z. Genomic and phylogenetic characterization of Shewanella xiamenensis isolated from giant grouper (Epinephelus lanceolatus) in Taiwan. Zoonoses Public Health 2019, 66. [CrossRef]

11. Zong, Z. Nosocomial peripancreatic infection associated with Shewanella xiamenensis. J. Med. Microbiol. 2011, 60, 1387-1390. [CrossRef] [PubMed]

12. Tacao, M.; Correia, A.; Henriques, I. Environmental Shewanella xiamenensis strains that carry bla OXA-48 or bla $a_{\mathrm{OXA}-204}$ genes: Additional proof for bla $\mathrm{OXX}_{-48}-\mathrm{like}$ gene origin. Antimicrob. Agents Chemother. 2013, 57, 6399-6400. [CrossRef] [PubMed]

13. Potron, A.; Poirel, L.; Nordmann, P. Origin of OXA-181, an emerging carbapenem-hydrolyzing oxacillinase, as a chromosomal gene in Shewanella xiamenensis. Antimicrob. Agents Chemother. 2011, 55, 4405-4407. [CrossRef] [PubMed]

14. Tacao, M.; Araujo, S.; Vendas, M.; Alves, A.; Henriques, I. Shewanella species as the origin of bla $a_{\text {OXA-48 }}$ genes: Insights into gene diversity, associated phenotypes and possible transfer mechanisms. Int. J. Antimicrob. Agents 2018, 51, 340-348. [CrossRef] [PubMed]

15. Zong, Z. Discovery of bla OXA-199, a chromosome-based bla OXA-48-like variant, in Shewanella xiamenensis. PLoS ONE 2012, 7, e48280. [CrossRef]

16. Tafoukt, R.; Leangapichart, T.; Hadjadj, L.; Bakour, S.; Diene, S.M.; Rolain, J.M.; Touati, A. Characterisation of bla $a_{\mathrm{OXA}-538}$, a new variant of bla OXA-48, $_{\text {, }}$ in Shewanella xiamenensis isolated from river water in Algeria. J. Glob. Antimicrob. Resist. 2018, 13, 70-73. [CrossRef] [PubMed]

17. Poirel, L.; Walsh, T.R.; Cuvillier, V.; Nordmann, P. Multiplex PCR for detection of acquired carbapenemase genes. Diagn. Microbiol. Infect. Dis. 2011, 70, 119-123. [CrossRef]

18. Pasteran, F.; Tijet, N.; Melano, R.G. Simplified Protocol for Carba NP Test for Enhanced Detection of Carbapenemase Producers Directly from Bacterial Cultures. J. Clin. Microbiol. 2015, 53, 3908-3911. [CrossRef]

19. Waterhouse, A.; Procter, J.; Martin, D. Jalview Version 2-a multiple sequence alignment editor and analysis workbench. Bioinformatics 2009, 25, 1189-1191. [CrossRef] 
20. Skalova, A.; Chudejova, K.; Rotova, V. Molecular Characterization of OXA-48-Like-Producing Enterobacteriaceae in the Czech Republic and Evidence for Horizontal Transfer of pOXA-48-Like Plasmids. Antimicrob. Agents Chemother. 2017, 61. [CrossRef]

21. Kumar, S.; Stecher, G.; Li, M.; Knyaz, C.; Tamura, K. MEGA X: Molecular Evolutionary Genetics Analysis across Computing Platforms. Mol. Biol. Evol. 2018, 35, 1547-1549. [CrossRef] [PubMed]

22. Antonelli, A.; Di Palo, D.M.; Galano, A.; Becciani, S.; Montagnani, C.; Pecile, P.; Galli, L.; Rossolini, G.M. Intestinal carriage of Shewanella xiamenensis simulating carriage of OXA-48-producing Enterobacteriaceae. Diagn. Microbiol. Infect. Dis. 2015, 82, 1-3. [CrossRef] [PubMed]

23. Yousfi, K.; Touati, A.; Lefebvre, B.; Fournier, E.; Cote, J.C.; Soualhine, H.; Walker, M.; Bougdour, D.; Tremblay, C.; Bekal, S. A Novel Plasmid, pSx1, Harboring a New Tn1696 Derivative from Extensively Drug-Resistant Shewanella xiamenensis Encoding OXA-416. Microb. Drug Resist. 2017, 23, 429-436. [CrossRef] [PubMed]

24. Palaniyandi, S.; Mitra, A.; Herren, C.D.; Zhu, X.; Mukhopadhyay, S. LuxS contributes to virulence in avian pathogenic Escherichia coli O78:K80:H9. Vet. Microbiol. 2013, 166, 567-575. [CrossRef] [PubMed]

(C) 2019 by the authors. Licensee MDPI, Basel, Switzerland. This article is an open access article distributed under the terms and conditions of the Creative Commons Attribution (CC BY) license (http://creativecommons.org/licenses/by/4.0/). 